\title{
Queering Acts of Mourning in the Aftermath of Argentina's Dictatorship. The Performances of Blood
}

Cecilia Sosa (2014)

Londres, Tamesis Books, pp. 284.

\section{( María Marta Quintana IIDYPCa, UNRN, CONICET}

En nuestro país, las secuelas del terrorismo de Estado remiten casi sin solución de continuidad a las 'narrativas de la sangre', si se considera que, en su gran mayoría, las organizaciones conformadas para la búsqueda de las y los detenidos-desaparecidos por razones políticas y de las niñas y niños apropiados durante la última dictadura cívico-militar (1976-1983) se han articulado en la (mono)lengua del parentesco. Precisamente, el trabajo de Cecilia Sosa comienza por señalar cómo las Madres, Abuelas, Hijos, Hermanos, Familiares de las víctimas de la violencia estatal se han reconfigurado como una "familia herida" [wounded family] y más aún cómo, desde ese locus de enunciación -que es todo un espacio de domiciliación del archivo-, se han convertido en los guardianes del luto y la memoria. Al respecto, enfatiza la socióloga argentina, por más de treinta años dichas organizaciones han comandado el trabajo del duelo y transformado las luchas por la memoria en una cuestión familiar. Sin embargo, Queering Acts of Mourning... también viene a dar cuenta de un desplazamiento que, especialmente en la última década, ha comenzado a producirse en torno de la legitimidad y el derecho a recordar. Como irá mostrando su autora a lo largo de las páginas, ya no se trata de un patrimonio exclusivo de las víctimas 'directas', sino de un proceso colectivo que exhibe el modo en que el pasado nos toca, nos afecta, en cuanto comunidad.

A los fines de profundizar la crisis de la normatividad de la sangre, y de cuestionar su hegemonía hermenéutica - manifestando que dicha crisis no ha sido lo suficientemente advertida por las y los estudiosos tanto locales como internacionales del tema, quienes, en su mayor parte, no logran superar la clave narrativa del familismo y, por ende, expandir el análisis de los efectos sociales del trauma hacia una escala más amplia que la circunscripta a los organismos-, Sosa construye un marco alternativo que combina los estudios queer, los de performance y los de las emociones. Si la perspectiva queer le permite horadar la convencionalidad ritualizada del parentesco consanguíneo, en tanto - aclara siguiendo a Judith Butler-queer no es exclusivamente una forma de identificación lesbiana o gay, sino que es, más bien, una contestación crítica a la normatividad biologicista, mediante la combinación de los estudios de performance con el -denominado- 'giro afectivo', indaga en los efectos de la violencia de Estado más allá del paradigma de la víctima y desplaza la categoría de trauma como eje central del análisis. Pues, en esta última dirección, centrándose en escenificaciones que exceden la actuación del parentesco biológico, la autora prefiere hablar de actos de luto, que - si bien forman parte de una cultura pública del duelo-construyen respuestas afectivas alternativas al dolor, no necesariamente melancólicas ni asociadas al evento traumático; como lo son el placer, el humor, la esperanza y el entusiasmo.

El enfoque queer de Sosa trabaja, entonces, sobre una diversidad de materiales y de géneros (entrevistas, memorias, sesiones de cocina, films, obras teatrales y literarias) que dan cuenta de nuevos lenguajes y de formas no-victimizadoras para hablar de y tramitar la pérdida. Más precisamente, los artefactos que la autora elige para su estudio constituyen un contraarchivo de la labor del duelo que, como un doble espectral o un retorno de lo excluido, minan - desde dentro- tanto las narrativas familistas y heroicas de los desaparecidos como el privilegio epistémico de los afectados 'directos'. En este sentido, esos artefactos raros, excéntricos, provocan extrañamientos no solo porque ofrecen versiones a contracorriente de 
dichas narrativas, sino porque además traen a escena a los outsiders, esto es, a los marginales del duelo.

Escrito inicialmente como tesis doctoral en Drama (para la Queen Mary University of London), y coganadora de un premio a la mejor disertación, Queering Acts of Mourning... se organiza en seis capítulos, una introducción, una sección abocada a las conclusiones y escrita en ocho actos y un postscriptum. Cada capítulo se centra en alguno o algunos de los materiales que conforman el corpus de análisis, y explora el modo en que descentran las narrativas de los grupos de derechos humanos (DD. HH.) y producen respuestas no convencionales frente al dolor. Cabe señalar que, en general, esos descentramientos o desplazamientos han tenido lugar en el contexto enunciativo del kirchnerismo, el cual consagró el discurso de los organismos como discurso de Estado; por consiguiente, el libro también da cuenta de cómo los propios artefactos problematizan las implicancias de un discurso oficial-estatal de la memoria.

En el primer capítulo, Sosa rastrea la configuración del discurso de la consanguinidad no solo como una respuesta frente al (bio)poder dictatorial, sino también como un discurso privilegiado por el Estado de derecho para llevar adelante tanto las políticas de búsqueda de las y los desaparecidos como las políticas reparatorias para sus familiares. No obstante, ahí mismo, muestra un primer desplazamiento respecto del modelo tradicional de familia (invocado por gran parte de los grupos de DD. HH.), haciendo foco en la histórica expresión de las Madres: "Nuestros hijos nos dieron la vida". En esa inversión, que es mucho más que un trastocamiento en el orden de los términos, la autora encuentra el puntapié inicial para desandar la normatividad del parentesco biológico y profundizar en esas nuevas formas de afiliación política. En este lugar explora, además, otros artefactos y discursos, que - siguiendo a Sara Ahmed-denomina 'aguafiestas' [killjoy], en tanto exhiben ciertos infortunios familiares; como sucede, por ejemplo, con el Diario de una princesa montonera. $110 \%$ verdad (2012), de Mariana Eva Pérez.

El capítulo siguiente se centra en el particular humor negro de H.I.J.O.S. y analiza el modo en que, a través de él, la agrupación revierte la vergüenza y la injuria vividas en cuanto hijos/as de desaparecidos/as - especialmente durante los años noventa, época caracterizada por la impunidad-. Pero, asimismo, merodeando esa estrategia, Sosa muestra cómo, al mismo tiempo, por medio de la producción de una forma placentera - vinculada, en este caso, con el humor-que rompe con la victimización, los jóvenes construyen y refuerzan una suerte de pedigree (relacionado con el número de familiares desaparecidos, pertenencias políticas, tipo de militancia) y trazan jerarquías hacia el interior de la organización y delimitaciones respecto de su exterior. Al respecto, advierte que el sentido del humor de H.I.J.O.S. es solidario de una idea restrictiva de 'nosotros' que, no obstante, será resignificada en contextos más recientes.

En el tercer capítulo, la autora examina tres films: Los rubios (2003), de Albertina Carri; M (2007), de Nicolás Prividera; y La mujer sin cabeza (2008), de Lucrecia Martel, los cuales, desde su punto de vista, tienen en común una crítica al 'culto de la víctima'. Si Los rubios -a través de sus procedimientos retóricos- rechaza las evocaciones nostálgicas del pasado y difumina las fronteras entre ficción y testimonio, cuestionando de ese modo la verosimilitud de este último que se funda en (la verdad de) la sangre, $M$ deja entrever nuevas aristas de la experiencia del trauma y de ciertas expectativas sociales vinculadas con la memoria. Prividera, director y protagonista del film, no solo no oculta su enojo frente a las narrativas heroicas de las y los desaparecidos, sino que - para Sosa - lo transforma en un provocativo sentimiento para recrear la comunidad de los afectados. De ambos filmes, y sin soslayar las tensiones que se producen entre uno y otro, en particular entre sus directores/as, la autora destaca las rupturas que generan con el modelo del trauma y la filiación consanguínea, haciendo del luto una experiencia extendida hacia otros públicos. En esta última dirección, centrándose en el argumento de la película de Martel, despliega una interesante reflexión en torno de la complicidad social con el terrorismo de Estado. Así, al poner en diálogo las tres películas, evidencia un funcionamiento contracitacional, que además de contribuir al advenimiento de una nueva cultura del luto da lugar a otras formas no-normativas de responsabilidad.

El cuarto capítulo se enfoca en las sesiones de cocina brindadas por Hebe de Bonafini en el Centro Cultural "Nuestros hijos", radicado en la ex ESMA. Aquí, Sosa analiza la performance de la Madre y juega con la idea de una Eucaristía secular, esto es, de una conversión política llevada a cabo a través del ritual de la comida. Complejizando la noción de 'posmemoria' (de Marianne Hirsch), algo que hace a lo largo de todo su trabajo, señala que dicha actuación supone una modalidad alternativa de duelo público, que excede a la comunidad de los directamente afectados y que conlleva, a la par, una crítica a las políticas de la memoria fundadas en la normatividad de la sangre y las prerrogativas de la 'familia herida'. Para la socióloga, por medio de esas sesiones no solo se produce 
la conversión de un lugar de muerte en un lugar de encuentro, sino también la transformación de la congregación de los que tienen derecho a recordar. Y enfatiza que, en esa escena secular, Bonafini emerge como una líder con la habilidad para crear nuevos espacios, más hospitalarios de las audiencias 'extranjeras' a las narrativas más tradicionales del dolor.

En el capítulo que sigue, ofrece una sugerente lectura de Mi vida después (2009), la pieza teatral de Lola Arias (quien, advierte nuestra autora, carece de pedigree). A propósito, le interesa mostrar cómo la generación que no fue testigo directo del pasado traumático construye nuevas memorias y filiaciones en el presente-futuro. Porque si bien los actores y actrices del bio-drama de Arias se visten -emulando una especie de viaje en el tiempo-con las ropas de sus progenitores/as (o sea, de la generación precedente), la representación vicaria y la memoria literal fracasan, pero, justamente, habilitando otro proceso de (re)significación del pasado y de construcción de responsabilidad. De este modo, para Sosa, Mi vida después - que al igual que Los rubios desgasta los bordes entre realidad y ficción y subvierte las fronteras entre la historia privada y la pública- exhibe la capacidad que tiene el teatro para transformar el trauma y arrojar nuevos sentidos, incluso para las víctimas directas del terrorismo de Estado.

Por último, el sexto capítulo se centra en la novela Los topos (2008), de Félix Bruzzone. En este lugar, la socióloga destaca la posición de 'doble agente' del autor, dada su condición de hijo de desaparecidos, y la parodia que Los topos despliega en torno de la concepción de parentesco de los grupos de DD. HH. Más precisamente, muestra cómo la novela interrumpe la perfomatividad del discurso de los organismos, señalando las contradicciones y limitaciones que tiene la oficialización de dicho discurso como discurso de Estado, y la desvía hacia otros contextos. Pues por medio de personajes y de neo-desaparecidos LGBT+, Los topos manifiesta que, al igual que las transgresiones de género, las conversiones políticas no se detienen en un punto ulterior, es decir, biológico. En la perspectiva de Sosa, la ficción de Bruzzone es una magnífica expresión de la configuración de subjetividades alternativas, que desplazan radicalmente las performances del ADN como única forma de actuación, y de la posibilidad de imaginar una comunidad futura, no-convencional, que emerge de la experiencia común del dolor, pero que conduce hacia otras modalidades de amor y cuidado que no atañen exclusivamente al legado de la sangre.

La posibilidad -y necesidad - de recrear la comunidad de los afectados es una idea matriz que recorre todo el libro. Por eso, a través de su derrotero analítico, la autora muestra cómo la repetición del trauma y del discurso de la sangre no supone una mera iteración, sino la posibilidad de romper con la historicidad a la que están sometidos y dar lugar a nuevas narrativas e identificaciones 'pos-sanguíneas'. En este sentido, los artefactos y performances queer que analiza con irreprochable lucidez, al someter a crítica la normatividad del familismo biológico y cuestionar la 'familia herida' como única víctima de la violencia estatal, abren un espacio para las y los outsiders. Es decir, hacen lugar a aquellos que sin haber sido testigos directos o directamente afectados por dicha violencia también han experimentado el dolor y la pérdida; y que, por consiguiente, reivindican para sí el legítimo derecho a recordar y significar el pasado(presente-futuro). Justamente, este es el punto de vista que asume la socióloga, quien, además, reclama para su propio trabajo el estatuto de 'aguafiestas' (que le atribuye a la mayor parte de sus materiales). $Y$ tiene razón porque, en efecto, Queering Acts of Mourning... sobresale por su falta de condescendencia con las narrativas del familismo (y con cualquier forma de happy endings), como también por su compromiso con la reinvención de una política del luto, en la que la responsabilidad - siempre abierta al porvenir-no se funda en el poder de la sangre, sino en una elección y relacionalidad profundamente éticas.

En conclusión, sin haber agotado la riqueza y sofisticación de sus análisis, el trabajo de Cecilia Sosa resulta un aporte indispensable para quienes nos abocamos al estudio interdisciplinario de la memoria y la historia reciente; y una grata experiencia de lectura, dadas las virtudes literarias de su autora. 
